\title{
Is age kinder to females than to males?
}

\author{
ELIZABETH J. MEINZ and TIMOTHY A. SALTHOUSE \\ Georgia Institute of Technology, Atlanta, Georgia
}

\begin{abstract}
To investigate possible gender differences in the patterns of age-cognition relations, a metaanalysis was conducted on the data from 25 studies (5,201 participants) by the second author and his collaborators. Gender and age differences consistent with prior reports were found, but there were few measures on which the age $\times$ gender interactions were significant. Although the majority of neuroimaging studies investigating gender differences in age-related atrophy and functional decline report greater age-related differences in males, the only significant interactions on the cognitive measures in this study (on measures of speed and reasoning) were in the direction of lesser agerelated declines for males than for females.
\end{abstract}

Age-related differences have been reported on various measures of cognitive functioning, frequently in the direction of lower levels of performance with increased age (for reviews, see Blanchard-Fields \& Hess, 1996, and Craik \& Salthouse, 1992). Gender-cognition relations are also well documented, with higher performance in males on some measures, such as spatial abilities, and higher performance in females on others, such as verbal abilities (for reviews, see Halpern, 1992, and Maccoby \& Jacklin, 1974). Although this pattern of gender-cognition relations reportedly remains relatively stable across age (Schaie, 1996)for example, the male advantage in spatial abilities is evident throughout the lifespan (Willis \& Schaie, 1988)-the interrelations among age, gender, and cognition have received little attention. In other words, although the qualitative pattern of gender differences in performance may remain stable across the lifespan, it is not yet clear whether the quantitative relations between age and cognitive performance are the same for females and males. An interaction of age and gender might be expected in light of recent reports of gender differences in age-related decline on some measures of brain morphology and functioning.

For example, Gur et al. (1991) reported that, although men and women showed similar patterns of age-related decline in brain volume, there was a significant interaction of age and gender on another measure of brain atrophy, cerebral spinal fluid volume (CSF). Men showed greater age-related increases in CSF than did women, suggesting more pronounced atrophy with advancing age in males than in females. Interactions of age and gender were also found in ratios of ventricular to sulcal volume because there was no gender effect in the rate of ventricular atrophy, but men had greater age-related sulcal atrophy than did

This research was supported by NIA Training Grant AG00175 to E.J.M. and NIA Grant R37 6826 to T.A.S. The authors gratefully acknowledge the helpful comments of Paul Verhaeghen, Diane Halpern, David Lane, Lars-Göran Nilsson, and one anonymous reviewer. Correspondence should be addressed to E. J. Meinz, School of Psychology, Georgia Institute of Technology, Atlanta, GA 30309 (e-mail: gt4956b @acme.gatech.edu) women. There were also gender differences in the hemispheric patterns of age-related atrophy; women showed similar atrophy across the hemispheres, but men showed greater atrophy in the left ventricles than in the right ventricles. The first two findings, that of larger increases with age in males on overall CSF and sulcal CSF, suggest greater age-related brain atrophy in men than in women, and the third finding indicates that males show greater age-related decline in left hemisphere structures but not right hemisphere structures.

Kaye, DeCarli, Luxenberg, and Rapoport (1992) also found that the onset of large age-related declines in brain volume occurred earlier in men (beginning in the 1950s) than in women (beginning in the 1960s). Additionally, gender differences in the relation of age to brain changes have been found with females exhibiting smaller declines in the caudate nucleus and putamen (Raz, Torres, \& Acker, 1995), and in whole brain, frontal, and temporal lobe volume (Cowell et al., 1994; Murphy et al., 1996). However, males showed less age-related loss of hippocampal and parietal volume (Murphy et al., 1996).

A few studies have used measures of brain functioning rather than structure when investigating age-gender relations. In measures of slow electrophysiological activity, Duffy, McAnulty, and Albert (1993) found greater agerelated activity reductions in men than in women. Gender differences in the relation of age to measures of brain metabolism have also been reported, with greater metabolic declines in the left hemispheres than in the right hemispheres of men, but either greater metabolic decline in the right hemispheres or equal metabolic decline across the hemispheres in women (Murphy et al., 1996). These results are consistent with the structural findings of Gur et al. (1991), and they extend them with functional evidence.

Although the preceding studies provide fairly strong evidence for age-gender interactions in brain structure and function, several authors have noted that it is desirable to determine whether similar interactions exist with behavioral data (e.g., Cowell et al., 1994; Gur et al., 1991; Raz et al., 1995). Isolated studies have investigated the effects of gender on age-cognition relations with specific cogni- 
Table 1

Descriptions of Included Studies

\begin{tabular}{|c|c|c|c|c|c|c|}
\hline \multirow[b]{2}{*}{ Study } & \multirow[b]{2}{*}{$N$} & \multicolumn{2}{|c|}{$n$} & \multicolumn{2}{|c|}{ Age } & \multirow[b]{2}{*}{ Citation } \\
\hline & & Males & Females & $M$ & $S D$ & \\
\hline 1 & 202 & 59 & 143 & 54.6 & 18.3 & Hambrick, Salthouse, \& Meinz (1997, Study 1) \\
\hline 2 & 218 & 91 & 127 & 53.3 & 14.0 & Hambrick, Salthouse, \& Meinz (1997, Study 2) \\
\hline 3 & 195 & 86 & 109 & 51.5 & 15.7 & Hambrick, Salthouse, \& Meinz (1997, Study 3) \\
\hline 4 & 128 & 43 & 85 & 46.1 & 15.6 & Meinz \& Salthouse (1998) \\
\hline 5 & 221 & 86 & 135 & 48.5 & 17.4 & Salthouse (1991, Study 1) \\
\hline 6 & 228 & 125 & 103 & 50.3 & 17.7 & Salthouse (1991, Study 2) \\
\hline 7 & 223 & 110 & 113 & 49.2 & 17.6 & Salthouse (1991, Study 3) \\
\hline 8 & 100 & 53 & 47 & 45.0 & 17.4 & Salthouse (1992) \\
\hline 9 & 305 & 124 & 181 & 51.1 & 16.6 & Salthouse (1993) \\
\hline 10 & 240 & 87 & 153 & 48.1 & 15.9 & Salthouse (1994a, Study 1) \\
\hline 11 & 125 & 60 & 65 & 51.5 & 16.5 & Salthouse (1994a, Study 2) \\
\hline 12 & 246 & 95 & 151 & 46.6 & 17.0 & Salthouse (1994b, Study 1) \\
\hline 13 & 258 & 102 & 156 & 48.7 & 17.0 & Salthouse (1994b, Study 2) \\
\hline 14 & 173 & 81 & 92 & 46.5 & 19.6 & Salthouse (1995a) \\
\hline 15 & 117 & 57 & 60 & 49.0 & 16.4 & Salthouse (1995b, Study 2) \\
\hline 16 & 178 & 61 & 117 & 49.0 & 20.1 & Salthouse (1996) \\
\hline 17 & 227 & 111 & 116 & 50.7 & 16.8 & Salthouse \& Babcock (1991, Study 1) \\
\hline 18 & 233 & 94 & 139 & 46.9 & 16.4 & Salthouse \& Babcock (1991, Study 2) \\
\hline 19 & 131 & 80 & 51 & 46.1 & 20.0 & Salthouse, Fristoe, Lineweaver, \& Coon (1995) \\
\hline 20 & 259 & 95 & 164 & 51.4 & 18.4 & Salthouse, Fristoe, \& Rhee (1996) \\
\hline $2 \mathrm{I}$ & 197 & 83 & 114 & 49.6 & 17.4 & Salthouse, Hancock, Meinz, \& Hambrick (1996) \\
\hline 22 & 139 & 58 & 71 & 47.7 & 16.4 & Salthouse, Kausler, \& Saults (1988, Study 1) \\
\hline 23 & 233 & 108 & 125 & 48.5 & 17.3 & Salthouse, Kausler, \& Saults (1988, Study 2) \\
\hline 24 & 242 & 102 & 140 & 49.1 & 17.5 & Salthouse \& Meinz (1995) \\
\hline 25 & 383 & 186 & 197 & 46.0 & 16.8 & Salthouse \& Mitchell (1990) \\
\hline 26 & 2,411 & 1,129 & 1,282 & 36.8 & 19.6 & Woodcock-Johnson standardization data \\
\hline
\end{tabular}

tive or neuropsychological tests. For instance, in one of three verbal memory tests, Larrabee and Crook (1993) found a significant interaction of age and gender, such that females showed less age-related decline than did males, but, in an earlier study, no significant interactions were found on these types of tests (Larrabee, Trahan, Curtiss, \& Levin, 1988). In a study by Elias, Robbins, Walter, and Schultz (1993), a large battery of neuropsychological tests was administered, but a significant interaction of age and gender was found only on the Halstead-Reitan category subtest. Interactions of age and gender were tested in a study of gender-related episodic and semantic memory differences by Herlitz, Nilsson, and Bäckman (1997), but no significant interactions were found.

Schaie (1996) summarized the findings of the Seattle longitudinal study, stating

age-difference patterns appear generally invariant across sex within domains (albeit there is strong evidence for overall gender differences in level of performance), but it is not a foregone conclusion that such invariance holds for all abilities or for all markers of a given ability. (p. 83)

This statement implies that more thorough investigations of the interrelations among age, gender, and cognitive performance are needed.

The purpose of the present study was to conduct such a systematic investigation using meta-analytic procedures. However, because the requisite information for a metaanalysis of this type (i.e., effect size estimates for the age $\times$ gender interaction) is seldom reported, the present analyses are based on raw data from studies conducted by T. A. Salthouse and his collaborators over the past 10 years.

\section{METHOD}

\section{Selection of Studies}

The primary analysis focused on raw data from 25 cross-sectional studies conducted by T. A. Salthouse and his collaborators. All of these studies included both male and female participants of a continuous age range. Participants in all of the studies were recruited through newspaper ads, community groups, or personal contacts, and no special appeals were made in the studies to either females or males. To the best of our knowledge, none of these individuals participated in more than one of the included studies. Performance measures from all of the cognitive variables in these studies were included. There were a total of 5,201 participants and 74 different variables across these studies. Although this was not a typical metaanalysis (for the reasons described earlier), the results of the analyses should be broadly generalizable because the age relations in these data have been found to be similar to those reported by other investigators (i.e., Verhaeghen \& Salthouse, 1997).

Data from the most recent standardization of the WoodcockJohnson test battery (Woodcock \& Johnson, 1989, 1990) were also included in a separate analysis to be compared with the results of the primary analysis. ${ }^{1}$ Data on 35 variables from 2,411 participants between 18 and 94 years of age were available in this data set. Characteristics of the participants from each of the studies, including age and gender distributions, are reported in Table 1.

\section{Classification of the Tasks}

All tasks were classified as one of eight types: speed, spatial, primary memory/working memory, episodic memory, reasoning, knowledge, verbal fluency, and miscellaneous. Brief descriptions of all tasks included in the meta-analysis are listed by task classifica- 

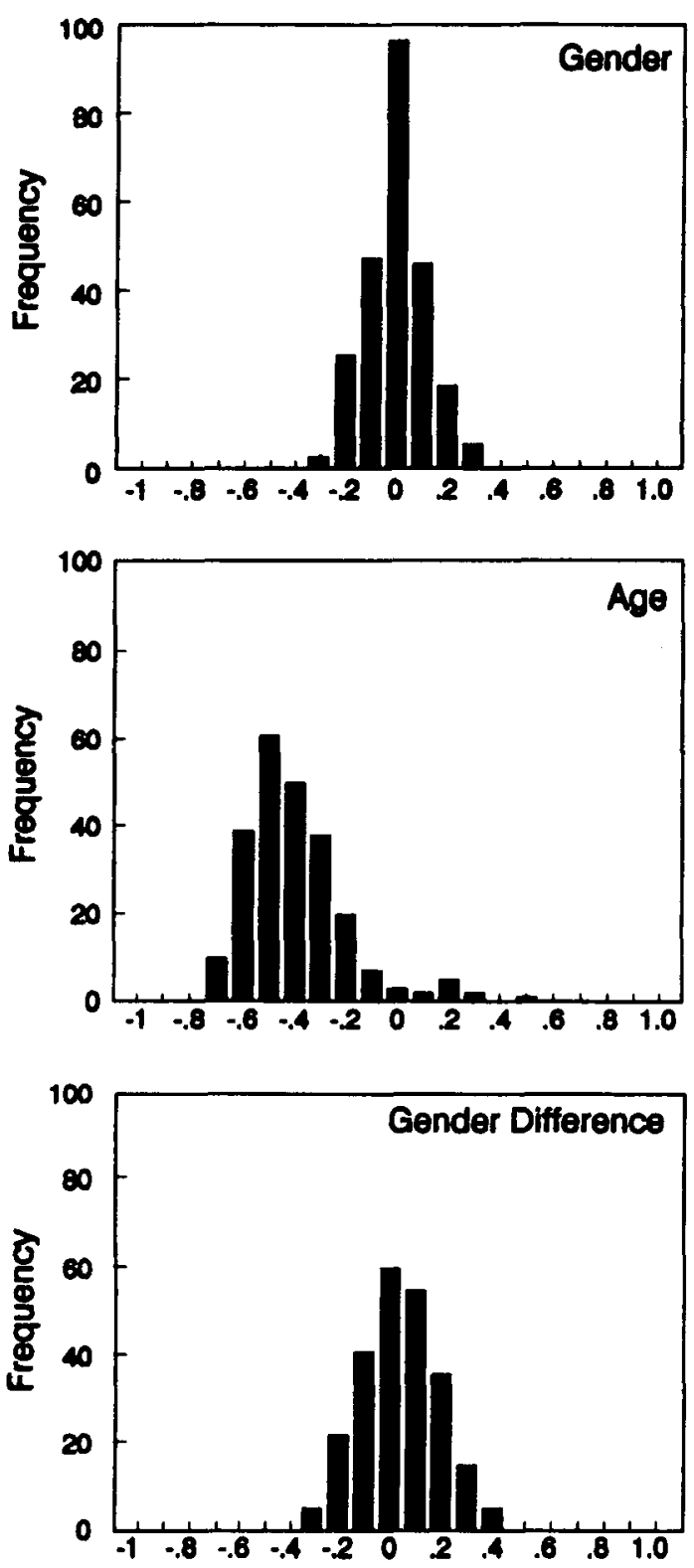

Figure 1. Gender, age, and gender difference in age-correlation effect-size frequencies for all variables in the primary studies. Note that the observations are not independent because the correlations are based on individual variables, and, thus, several measures of the same task classification may be included from a single study. A total of $\mathbf{2 4 0}$ correlations are included in each distribution.

tion in Appendix A. These classifications were chosen because they represent distinct categories of cognitive tasks with differing levels of age-performance relations. Although classification by type of stimulus material (i.e., verbal, spatial, numerical, etc.) is also a viable option (because gender differences have been studied using these classifications), it was decided that this level of analysis might be more appropriate for homogeneity analyses if, in fact, heterogeneity within the classifications was found.

The variables from the Woodcock-Johnson data were grouped in a similar manner and according to the abilities that the tasks are purported to measure whenever possible.

\section{Procedure}

Effect sizes. Following the suggestion of Rosenthal (1991), the Pearson product-moment correlation coefficient, $r$, was chosen as a measure of effect size in these analyses. All variables were scaled so that higher scores indicated higher levels of performance, and, therefore, negative correlations with age indicated age-related decline. Gender was coded such that males were assigned scores of 0 and females were assigned scores of 1 ; consequently, positive gender effects indicate higher levels of performance in females, and negative gender effects indicate higher levels of performance in males.

To express the age $\times$ gender interaction as an effect size, a difference score was computed between the age effect sizes for males and for females by first converting each age correlation to a Fisher $z$, subtracting these $z \mathrm{~S}$, and then converting the $z_{\text {diff }}$ back to an $r_{\text {diff }}{ }^{2}$ Effect sizes for females were subtracted from those for males; thus, a negative value indicates greater age-related decline in males than in females, and a positive value indicates greater age-related decline in females than in males. To illustrate, if the age effect on a variable was -.6 for males and -.4 for females, $r_{\text {diff }}$ is equal to the $z$ transformation of the male effect size ( -.69$)$ minus the $z$ transformation of the female effect size $(-.42)$, which is equal to -.27 . When converted back into the correlation metric, this negative difference score $\left(r_{\text {diff }}=-.26\right)$ indicates greater decline among males than females. ${ }^{3}$ For illustrative purposes, the distributions of effect sizes for gender, age, and the gender difference in age correlations across all variables $(N=240)$ are shown in Figure 1. It should be noted that the range of effect sizes in these histograms is relatively narrow and that only the distribution of effect sizes for age was not centered at zero.

In order to avoid the stochastic dependence that would result from using several indices of one cognitive ability from the same study and the same participants, a single effect size measure was derived for each study in a given task classification. For instance, for each study that included tasks classified as measuring speed, only one effect size was used in the analyses, regardless of whether the particular study included 1 or 10 speed variables. To obtain this average effect size, the effect sizes for each task were transformed via Fisher's $r$-to- $z$ transformation, and then the $z S$ were averaged to yield a $z_{\text {average }}$ Finally, the $z_{\text {average }}$ was converted back to an effect size measure $\left(r_{\text {average }}\right)$. The average effect sizes for the studies in the primary analysis are listed in Appendix B.

Effect size estimation. Mean weighted effect sizes $(r+)$ were computed across studies for gender, age, and the age $\times$ gender interaction term for each task classification. These weighted coefficients and their $95 \%$ confidence intervals were computed by assigning weights to each study on the basis of sample sizes, as described in Rosenthal (1991) and in Hedges and Olkin (1985). Weighted effect size estimates and confidence intervals for each task classification in the primary analysis are presented in Table 2 .

Tests for homogeneity of effect sizes within the task classifications were also performed by computing $Q_{\mathrm{T}}$, a measure of total homogeneity, and comparing this value to the critical value established by the chi-square distribution. If the effect size estimates are found to be heterogeneous (i.e., if $Q_{\mathrm{T}}$ exceeds the critical value), moderators may be tested. Successful moderators are those that yield homogeneous within-group variance, $Q_{\mathrm{W}}$, and heterogeneous betweengroup variance, $Q_{\mathrm{B}}$. For instance, if $Q_{\mathrm{T}}$ reveals heterogeneity in the measure of speed, the task medium may be identified as a potential moderator, and the group may be divided into paper-and-pencil and computerized tasks. The goal of subsequent analyses would be to demonstrate that there was significant variance between the moderator groups $\left(Q_{\mathrm{B}}\right)$, but there was little variance within each of the groups ( $Q_{\mathrm{W}}$ for paper-and-pencil tasks and $Q_{\mathrm{W}}$ for computerized tasks).

\section{Woodcock-Johnson Analyses}

Age, gender, and age $\times$ gender interaction effect sizes were computed for each task in the Woodcock-Johnson data. These effect sizes were averaged within task classifications to produce mean effect sizes that could be compared with the weighted mean effect 
Table 2

Mean Weighted Correlations, $95 \%$ Confidence Intervals, and Homogeneity Statistics for Task Classifications in the Primary Analysis

\begin{tabular}{|c|c|c|c|c|c|c|c|}
\hline Task Type & Effect & $k$ & $N$ & $r+$ & LL/UL & $Q_{T}$ & Pattern \\
\hline Speed & & 24 & 4,964 & & & & \\
\hline & Gender & & & .04 & $.02 / .07$ & 29.28 & $\mathbf{F}>\mathbf{M}$ \\
\hline & Age & & & -.50 & $-.53 /-.48$ & $80.68^{*}$ & $\mathrm{Y}>\mathrm{O}$ \\
\hline & Male & & & -.49 & $-.51 /-.47$ & $131.10^{*}$ & \\
\hline & Female & & & -.52 & $-.54 /-.50$ & $82.60^{*}$ & \\
\hline & Gender difference & & & .05 & $.02 / .07$ & $73.61^{*}$ & $\mathrm{~F}_{\mathrm{Y}}>_{\mathrm{O}}>\mathrm{M}_{\mathrm{Y}}>_{\mathrm{O}}$ \\
\hline Spatial & & 11 & 2,585 & & & & \\
\hline & Gender & & & -.18 & $-.22 /-.14$ & 11.76 & $M>F$ \\
\hline & Age & & & -.36 & $-.39 /-.32$ & $24.83^{*}$ & $\mathrm{Y}>\mathrm{O}$ \\
\hline & Male & & & -.35 & $-.38 /-.32$ & $57.00^{*}$ & \\
\hline & Female & & & -.36 & $-.40 /-.33$ & $28.50^{*}$ & \\
\hline & Gender difference & & & .01 & $-.02 / .05$ & $50.45^{*}$ & n.s. \\
\hline Primary/Working memory & & 14 & 2,632 & & & & \\
\hline & Gender & & & -.07 & $-.11 /-.03$ & 4.46 & $M>F$ \\
\hline & Age & & & -.39 & $-.42 /-.35$ & $33.61^{*}$ & $\mathrm{Y}>\mathrm{O}$ \\
\hline & Male & & & -.39 & $-.42 /-.36$ & $44.80^{*}$ & \\
\hline & Female & & & -.39 & $-.42 /-.36$ & $46.73^{*}$ & \\
\hline & Gender difference & & & .00 & $-.04 / .04$ & $40.43^{*}$ & n.s. \\
\hline Episodic memory & & 12 & 2,460 & & & & \\
\hline & Gender & & & .03 & $-.01 / .07$ & $20.42^{*}$ & n.s. \\
\hline & Age & & & -.35 & $-.39 /-.32$ & $26.11^{*}$ & $\mathrm{Y}>\mathrm{O}$ \\
\hline & Male & & & -.36 & $-.39 /-.32$ & $39.44^{*}$ & \\
\hline & Female & & & -.37 & $-.41 /-.34$ & $32.40^{*}$ & \\
\hline & Gender difference & & & .02 & $-.02 / .06$ & $26.27^{*}$ & n.s. \\
\hline Reasoning & & 12 & 2,971 & & & & \\
\hline & Gender & & & -.05 & $-.09 /-.02$ & 10.73 & $M>F$ \\
\hline & Age & & & -.38 & $-.41 /-.35$ & $77.44^{*}$ & $\mathrm{Y}>\mathrm{O}$ \\
\hline & Male & & & -.35 & $-.38 /-.22$ & $148.60^{*}$ & \\
\hline & Female & & & -.41 & $-.44 /-.38$ & $48.99^{*}$ & \\
\hline & Gender difference & & & .07 & $.03 / .11$ & $76.51^{*}$ & $F_{Y}>_{O}>M_{Y}>_{O}$ \\
\hline Knowledge & & 7 & 1,380 & & & & \\
\hline & Gender & & & -.04 & $-.09 / .02$ & 1.71 & n.s. \\
\hline & Age & & & .23 & $.18 / .28$ & $21.00^{*}$ & $\mathrm{O}>\mathrm{Y}$ \\
\hline & Male & & & .23 & $.18 /, 28$ & $36.75^{*}$ & \\
\hline & Female & & & .23 & $.18 / .28$ & 10.83 & \\
\hline & Gender difference & & & .00 & $-.05 / .05$ & $18.59^{\star}$ & n.s. \\
\hline Verbal fluency & & 3 & 598 & & & & \\
\hline & Gender & & & .04 & $-.04 / .12$ & 4.21 & n.s. \\
\hline & Age & & & -.03 & $-.11 / .05$ & $19.37^{*}$ & n.s. \\
\hline & Male & & & -.04 & $-.12 / .04$ & $46.95^{*}$ & \\
\hline & Female & & & -.02 & $-.10 /-.06$ & $11.83^{*}$ & \\
\hline & Gender difference & & & -.02 & $-.10 / .07$ & $18.49^{*}$ & n.s. \\
\hline Miscellaneous & & 5 & 1,082 & & & & \\
\hline & Gender & & & .07 & $.01 / .13$ & 3.13 & $\mathrm{~F}>\mathrm{M}$ \\
\hline & Age & & & -.39 & $-.44 /-.34$ & $67.15^{*}$ & $\mathrm{Y}>\mathrm{O}$ \\
\hline & Male & & & -.38 & $-.43 /-.32$ & $86.92^{*}$ & \\
\hline & $\begin{array}{c}\text { Female } \\
\text { Gender difference }\end{array}$ & & & -.40 & $-.44 /-.35$ & $56.92^{*}$ & $n s$ \\
\hline
\end{tabular}

Note-Task type is the task classification formed from variables believed to measure a common cognitive ability; effect refers to the type of effect reported; $k$, number of studies inciuded in analysis; $N$, number of participants included in analysis; $r+$, mean weighted correlation; LL/UL, lower and upper limits of $95 \%$ confidence interval; $Q_{T}$, total homogeneity; $n . S$., nonsignificant; $F>M$, significantiy higher performance in females than in males; $M>F$, significantly higher performance in males than in females; $Y>O$, significantly higher performance in young participants than in older participants; $\mathrm{F}_{\mathrm{Y}}>_{\mathrm{O}}>\mathrm{M}_{\mathrm{Y}}>_{\mathrm{O}}$, significantly greater age-related decline in females than in males. ${ }^{*} p<.05$ (nonhomogeneity).

sizes in the primary data set. The Woodcock-Johnson task classifications and their mean effect sizes can be found in Table 3 .

\section{RESULTS}

\section{Gender Effects}

As shown in Table 2, significant gender differences were found in all task classifications except episodic memory, knowledge, and verbal fluency in the primary sample, with females outperforming males on tasks of speed $(r=$ $+.05)$ and in the miscellaneous category $(r=+.07)$. There was a small advantage in females for tests of verbal fluency $(r=+.04)$, but this difference was not statistically significant because the $95 \%$ confidence interval included zero. Males outperformed females on spatial tasks $(r=$ $-.18)$, primary memory/working memory tasks $(r=-.07)$, 
Table 3

Age and Gender Relations on the Woodcock-Johnson Test Battery

\begin{tabular}{lcccccc}
\hline \multicolumn{1}{c}{ Task Type } & $j$ & Gender $r$ & Age $r$ & Male & Female & $\begin{array}{c}\text { Age Effect }(r) \\
\text { in Age } r\end{array}$ \\
\hline Speed & 2 & .08 & -.62 & -.51 & -.64 & .18 \\
Primary/Working memory & 3 & .00 & -.31 & -.34 & -.28 & -.07 \\
Episodic memory & 2 & .04 & -.51 & -.55 & -.49 & -.09 \\
Reasoning & 2 & -.01 & -.49 & -.50 & -.49 & -.01 \\
General knowledge & 3 & -.04 & -.28 & -.32 & -.24 & -.09 \\
Vocabulary & 3 & .05 & -.08 & -.14 & -.04 & -.10 \\
Auditory processing & 3 & .03 & -.45 & -.50 & -.43 & -.09 \\
Visual processing & 2 & .09 & -.49 & -.51 & -.47 & -.06 \\
Quantitative & 2 & -.15 & -.30 & -.29 & -.30 & .01 \\
Miscellaneous & 13 & .10 & -.26 & -.30 & -.25 & -.06 \\
\hline
\end{tabular}

Note-Task type is the task classification formed from variables believed to measure a common cognitive component; $j$, number of variables contributing to effect size; gender $r$, point-biserial correlation with gender (male $=0$, female $=1$ ); age $r$, correlation with chronological age; age $r$ for males/females, see Table 1 for number of male and female participants; gender difference in age $r$, age $\times$ gender interaction term expressed as $r_{\text {age }}$ (male) $-r_{\text {age }}$ (female).

and tests of reasoning $(r=-.08)$. In general, with the exception of the measures of spatial abilities, the gender effects were quite small.

\section{Age Effects}

Because all tasks were scored such that higher scores indicate higher levels of performance, negative age correlations reflect lower scores associated with increased age on a task. As shown in Table 2, in the primary data set, there were significant negative age correlations on tasks of speed $(r=-.50)$, spatial abilities $(r=-.36)$, primary memory/ working memory $(r=-.39)$, episodic memory $(r=-.35)$, reasoning $(r=-.38)$, and on the miscellaneous tasks $(r=$ $-.39)$, and there were significantly positive effects of age on the measures of knowledge $(r=+.23)$. There was no significant effect of age on verbal fluency.

\section{Age $\times$ Gender Interactions}

As noted above, the difference scores that serve as effect size indicators of gender $\times$ age interactions were computed by subtracting female age correlations from male age correlations; thus, negative difference score effect sizes indicate larger age-related decline in males, and positive difference score effect sizes indicate larger agerelated decline in females. Table 2 reveals significant gender differences in the magnitude of age effects on measures of speed $(r=+.05)$ and reasoning $(r=+.07)$, in both cases in the direction of somewhat smaller age-related decline in males than in females.

\section{Moderator Variable Analyses}

Because almost all of the $Q_{\mathrm{T}}$ statistics were significant (see Table 2), indicating heterogeneity of variance within task classifications, several analyses were performed in an attempt to identify moderators of the effects within each classification. For instance, speed tasks were divided into two groups: paper-and-pencil tasks and reaction time (computerized) tasks. Episodic memory, primary memory/working memory, and reasoning tasks were divided into groups by the type of material used: verbal, spatial, numerical, or symbolic (e.g., the unfamiliar symbols used in associative learning tasks). Finally, spatial tasks were divided into computerized and noncomputerized tasks. In order to compute between-group homogeneity statistics, $Q_{\mathrm{B}}$, independent moderator classes must be formed to avoid comparing classes containing the same participants. For example, if a study contains both paper-and-pencil and reaction time measures of speed, then either the paperand-pencil measure or the reaction time measure may be included in the moderator analyses, but not both. The assignment of each task classification to a moderator class was random whenever more than one class of task existed within a study.

Table 4 presents the gender, age, and difference score effect sizes and the $Q_{\mathrm{T}}$ or $Q_{\mathrm{W}}$ statistics for each task classification or moderator class for episodic memory, primary memory/working memory, reasoning, spatial abilities, and speed (no moderators of knowledge, verbal fluency, or miscellaneous tasks were identified and tested). For none of these potential moderators was the desired outcome of between-group heterogeneity and within-group homogeneity obtained; thus, there is little convincing evidence that the effect sizes varied systematically as a function of these factors. At the present time, therefore, we are unable to account for the significant variability within the various task classifications. Nevertheless, it should be noted that the confidence intervals for most of the effect size estimates were fairly narrow, and, thus, the withincategory variability does not preclude conclusions about overall effect sizes in the various classifications.

One point of interest revealed in the moderator analyses is that the gender effects on some of the task classifications seem to be a result of differential gender relations across moderator classes. For instance, closer inspection of the nonsignificant gender effect on episodic memory tasks reveals that there were significant gender effects in the direction of higher performance in females on verbal episodic tasks, but nonsignificant gender effects on sym- 
Table 4

Gender, Age, and Interaction Effect Sizes and Homogeneity Statistics According to Task Classification and Moderator Classes

\begin{tabular}{|c|c|c|c|c|c|c|c|c|}
\hline \multirow[b]{2}{*}{ Task Classification } & \multirow[b]{2}{*}{ Moderator Class } & \multirow[b]{2}{*}{$k$} & \multicolumn{2}{|c|}{ Gender } & \multicolumn{2}{|c|}{ Age } & \multicolumn{2}{|c|}{ Gender } \\
\hline & & & $r+$ & $Q_{\mathrm{T}}$ or $Q_{\mathrm{W}}$ & $r+$ & $Q_{\mathrm{T}}$ or $Q_{\mathrm{W}}$ & Diff $r+$ & $Q_{\mathrm{T}}$ or $Q_{\mathrm{W}}$ \\
\hline \multirow[t]{3}{*}{ Speed } & & 24 & $.04 *$ & 29.28 & $-.50^{*}$ & $80.68^{*}$ & $.05^{*}$ & $73.61^{*}$ \\
\hline & Reaction time/Computerized & 8 & .03 & $19.76^{*}$ & $-.48^{*}$ & 13.89 & -.01 & $16.28^{*}$ \\
\hline & Paper-and-pencil & 16 & $.06^{*}$ & 18.03 & $-.51^{*}$ & $60.81^{*}$ & $.08^{*}$ & $43.01^{*}$ \\
\hline \multirow[t]{3}{*}{ Spatial } & & 11 & $-.18^{*}$ & 11.76 & $-.36^{*}$ & $24.83^{*}$ & .01 & $50.45^{*}$ \\
\hline & Reaction time/Computerized & 3 & $-.17^{*}$ & 2.35 & $-.35^{*}$ & $7.58^{*}$ & $.15^{*}$ & 5.98 \\
\hline & Paper-and-pencil & 8 & $-.19^{*}$ & 9.25 & $-.37^{*}$ & $20.02 *$ & .00 & $44.84^{*}$ \\
\hline \multirow[t]{4}{*}{ Primary/Working memory } & & 14 & $-.07^{*}$ & 4.46 & $-.39 *$ & $33.61 *$ & .00 & $40.43^{*}$ \\
\hline & Numerical & 4 & $-.13^{*}$ & 3.79 & $-.35^{*}$ & 3.94 & .03 & $25.57^{*}$ \\
\hline & Spatial & 2 & $-.16^{*}$ & 0.37 & $-.43^{*}$ & 0.05 & -.04 & 3.51 \\
\hline & Verbal & 8 & -.03 & 4.51 & $-.37^{*}$ & $26.86^{*}$ & .00 & $36.98^{*}$ \\
\hline \multirow[t]{3}{*}{ Episodic memory } & & 12 & .03 & $20.42^{*}$ & $-.35^{*}$ & $26.11^{*}$ & .02 & $26.27^{*}$ \\
\hline & Symbolic & 7 & .00 & 12.04 & $-.31^{*}$ & 3.90 & .04 & $23.24^{*}$ \\
\hline & Verbal & 5 & $.09^{*}$ & $2.10^{*}$ & $-.40^{*}$ & $15.41^{*}$ & -.01 & 6.50 \\
\hline \multirow[t]{4}{*}{ Reasoning } & & 12 & $-.05^{*}$ & 10.73 & $-.38^{*}$ & $74.44^{*}$ & $.07^{*}$ & $76.51^{*}$ \\
\hline & Numerical & 2 & .00 & 2.21 & $-.36^{*}$ & 2.86 & $.19^{*}$ & $23.80^{*}$ \\
\hline & Spatial & 5 & -.06 & 6.26 & $-37^{*}$ & $33.48^{*}$ & .05 & $47.99^{*}$ \\
\hline & Verbal & 5 & -.04 & 2.86 & $-.42^{*}$ & $44.66^{*}$ & $.08^{*}$ & 6.44 \\
\hline
\end{tabular}

Note $-k$, number of studies included in analysis; $r+$, average weighted correlation; $Q_{\mathrm{T}}$ or $Q_{\mathrm{W}}$, total or within-class homogeneity. $Q_{\mathrm{T}}$ is reported for the task classifications (i.e., speed, spatial, primary memory/working memory, episodic memory, and reasoning), and $Q_{W}$ is reported for the moderator classes (i.e., reaction time/computerized, paper-and-pencil, numerical, spatial, verbal, and symbolic). $\quad$ * $p<.05$ (nonhomogeneity).

bolic episodic memory tasks. Similarly, the male advantage on primary memory tasks seems to be a result of higher levels of performance on numerical and spatial tasks, but not on verbal primary memory/working memory tasks. Also, the female advantage on speed tasks appears to be a result of superior female performance on paperand-pencil tasks, but not on reaction time speed tasks. With regard to the gender differences in age effects, differences in the direction of lesser age-related decline in males were more pronounced on verbal and numerical (relative to spatial) reasoning tasks, on computerized (relative to paper-and-pencil) spatial tasks, and on paper-andpencil (relative to reaction time) speed tasks. However, these results should be interpreted with caution because of the random assignment to moderator classes and the small number of studies within the moderator classes.

\section{Variance Analyses}

The correlation coefficients $(r)$ used here as an index of effect size are a function of the slope of the linear relationship between age and performance on the dependent variable, the variance of age, and the variance of the dependent variable. It is therefore possible that gender differences in the variance either on the dependent variables or on age could distort the comparisons of the age correlations between males and females. In other words, gender differences in the age correlation on a given dependent variable may be partially attributable to greater age variation or to greater variation in the dependent variable in one gender relative to the other. In fact, male children have been found to be more variable than female children in numerical and spatial abilities (see Maccoby \& Jacklin, 1974, for a review).
In order to examine this possibility, $F$ tests of equal variance were performed to compare the variances of age and of the dependent variables across gender. Because the raw dependent variables were in different units, they were converted to a common metric within each study by transforming them into standard scores based on the distribution of both males and females. The standard scores were then averaged to form one index of the dependent variable for each task classification within a given study.

Significant $F$ tests would indicate that the variance of females and males differed, and, if this were the case, the gender differences in age correlations might be partially attributable to a smaller range of variation in one gender than in the other. However, the results of these analyses, summarized in Appendix $\mathrm{C}$, indicate that there were no significant gender differences in the age variances, and there were significant gender differences in only 3 of 89 comparisons (one each in the speed, episodic memory, and miscellaneous categories) on the dependent variables. The small number of significant $F$ tests makes it unlikely that the pattern of results reported in this study were attributable to gender differences in the amount of variation in either age or the dependent variable. These results are also of substantive interest because they imply that, at least in these samples, adult males and females do not differ significantly with respect to interindividual variability on measures of cognitive abilities.

\section{Summary}

The pattern of gender-cognition relations in the primary data set was mixed, and, with the exception of the spatial measure, the effect sizes were quite small. There were large age effects on most of the variables, with negative ef- 
fects of age on measures of speed, spatial abilities, primary memory/working memory, and episodic memory, but positive effects of age on knowledge, and no age effects on verbal fluency. Small interactive effects of age and gender were found, with a significant advantage for males in speed and reasoning. The results of variance analyses suggested that it is unlikely that the results were influenced by gender differences in the variance of age or the variance of the dependent variables.

The Woodcock-Johnson data were analyzed for comparison with the primary data set. No confidence intervals could be established in this data set because each participant performed every task in the battery, and, thus, only the magnitude of the effects can be examined. Inspection of Table 3 reveals that gender effects in these data were small with the exception of a moderate gender effect in quantitative abilities, in the direction of higher levels of performance in males. The age trends were similar to those in the primary data set in that there were moderately negative effects of age on all measures except vocabulary. Surprisingly, the effects of age on knowledge in this data set were negative. As in the primary data set, the direction of the interaction effects were mixed. Greater age-related decline was evident among females on the measure of speed and among males on several of the other measures.

\section{DISCUSSION}

Although considerable effort has been devoted to documenting gender differences in the relations of age to brain morphology and functioning, few studies have confirmed these findings with behavioral data. A meta-analysis was therefore performed on 25 data sets encompassing a wide variety of cognitive tasks with the goal of examining age $\times$ gender interactions on cognitive measures. The main effects of age and gender were also examined for the purpose of comparison with the literature on gendercognition and age-cognition relations. Because most of the analyses revealed evidence of heterogeneity, it is possible that some true effects were concealed. Nevertheless, the confidence intervals for estimated effect sizes were relatively narrow, and, thus, the results can be considered reasonably precise.

The gender-cognition relations found in the primary data set were, for the most part, similar to those frequently reported in the literature. It should be noted that, while the present analysis revealed mostly male advantages, some measures at which females have been reported to excel (notably reading comprehension and writing) were not included (Halpern, 1992).

Males outperformed females in spatial abilities, which is consistent with the results of a meta-analytic review by Linn and Petersen (1986) and other reviews (e.g., Schaie, 1994). We found no significant gender differences on measures of verbal fluency or knowledge. Prior studies have been mixed on this issue because, while there have been some reports of a female advantage in general verbal abilities (Hyde \& Linn, 1986; Schaie, 1994), other analy- ses have revealed a female advantage on tests of anagram solution, general verbal abilities, and analogies, but no difference in vocabulary (Hyde \& Linn, 1986) or general knowledge (Herlitz et al., 1997). In this study, females were faster on tests of speed, but there was a male advantage in reasoning. The latter result is inconsistent with the work of Schaie (1994), in which a female advantage in tests of inductive reasoning was noted.

One inconsistency concerns the gender effects reported on episodic and primary memory tasks. Herlitz et al. (1997) investigated gender differences on episodic, semantic, and primary memory tasks. While they also reported no gender differences in semantic memory (which included tasks similar to those in the knowledge classification), they reported sizable gender differences on several episodic memory tasks, in the direction of higher levels of performance in females, and no gender differences on tests of primary memory. On closer inspection, however, the apparent discrepancies between the Herlitz et al. study and the present analyses are most likely attributable to the types of tasks used, because the moderator analyses revealed that, when considering only verbal tasks as in the Herlitz et al. study, there was a female advantage on episodic memory tasks, and there were no gender differences in primary memory/working memory tasks. These results suggest that the type of stimulus material (e.g., verbal, spatial) should always be considered when investigating gender differences in broad task classifications.

The gender relations in the Woodcock-Johnson data, for the majority of measures, were consistent with those in the primary data set. One exception is in the case of vocabulary, where females performed at higher levels than males did. The largest relation with gender in this data set was for the quantitative measures. Superior quantitative performance in males has been found by some researchers (Hyde, 1981; Schaie, 1994), but not others (Hyde, Fennema, \& Lamon, 1990). It is possible that these inconsistencies are simply the result of the magnitude of the gender effects; the effects are fairly small and greater than $r=.1$ on only two measures (spatial and quantitative).

The age-related effects in this study were similar to those reported in other cross-sectional studies in that substantial negative relations of age on measures of speed, primary memory/working memory, episodic memory, spatial abilities, and reasoning were found (see BlanchardFields \& Hess, 1996, and Craik \& Salthouse, 1992, for reviews). It remains to be seen whether comparable patterns would be evident in longitudinal designs, and results from more extensive sequential designs are needed before the source (i.e., endogenous or exogenous) of these effects can be identified.

Discrepancies existed between the Salthouse and Woodcock-Johnson data sets in terms of the relation of age to measures of knowledge. The data from Salthouse and collaborators suggest moderate positive age effects on measures of knowledge (general knowledge and vocabulary). Although there was a small positive age relation on the two vocabulary measures in the Woodcock-Johnson 
data, there was a negative relation between age and other measures of knowledge (general knowledge: social studies, science, and humanities). It is not clear whether the different patterns of age relations on measures of knowledge are due to differences in the nature of the samples (i.e., convenience samples vs. representative samples) or to other factors. One factor that could be involved is amount of education. While education level is very similar across age in the studies by Salthouse and his collaborators, the education level in the Woodcock-Johnson data decreases with age, reflecting population trends. However, this factor is not responsible for all of the differences in age-knowledge relations between the data sets, because a negative ageknowledge relation remains after statistical control of education in the Woodcock-Johnson data set.

The findings of primary interest in this study are those concerning the interactions of age and gender. Although the majority of results from studies based on neuroanatomical data suggest greater age-related atrophy and functional loss in males than in females, the only significant interactions found in the analysis of the primary data set were in the direction of greater age-related decline among females than among males. These data are consistent with Schaie's (1994) idea that, if anything, women decline earlier on some fluid abilities, such as perceptual speed and reasoning. Schaie also suggested that women show decline earlier on verbal fluency, and men on crystallized abilities, but these speculations were not supported in the present analyses. Moderator variable analyses suggested that gender differences in age-cognition relations may be related to the type of stimulus material (e.g., verbal, spatial) or method of task administration (e.g., computerized reaction time, paper-and-pencil), but more investigation is needed before strong conclusions can be drawn. The pattern of results in the Woodcock-Johnson data was mixed, but, again, almost all of the effects were very small.

In conclusion, the results of these analyses reveal that there are large (i.e., between $12 \%$ and $25 \%$ of the total variance) effects related to age, small (i.e., at most $3 \%$ of the variance) effects associated with gender, and small to nonexistent (i.e., less than $1 \%$ ) effects associated with interactions of age and gender on measures of cognitive performance.

As discussed in the introduction, evidence for differential patterns of aging between men and women has been reported with some neuroanatomical measures. However, these results have been somewhat inconsistent with respect to which gender exhibited greater age-related decline, and, apparently, no meta-analytic integrations of the neuroanatomical findings have been published. The most convincing resolution of the discrepancies between studies with neuroanatomical variables and with cognitive variables will likely require studies with moderately large samples of females and males from a wide age range who each contribute both neuroanatomical and cognitive data. Unless, and until, such studies yield strong evidence of significant age $\times$ gender interactions, any speculation about the basis for differential aging among females and males seems premature.

\section{REFERENCES}

Blanchard-Fields, F., \& Hess, T. M. (EDs.) (1996). Perspectives on cognitive change in adulthood and aging. New York: McGrawHill.

Cowell, P. E., Turetsky, B. I., Gur, R. C., Grossman, R. I., Shtasel, D. L., \& GUR, R. E. (1994). Sex differences in aging of the human frontal and temporal lobes. Journal of Neuroscience, 14, 4748-4755.

CRAIK, F. I. M., \& Salthouse, T. A. (Eds.) (1992). The handbook of aging and cognition. Hillsdale, NJ: Erlbaum.

DufFy, F. H., MCANulty, G. B., \& AlberT, M. S. (1993). The pattern of age-related differences in electrophysiological activity of healthy males and females. Neurobiology of Aging, 14, 73-84.

Elias, M. F., Robbins, M. A., WALter, L. J., \& Schultz, N. R. (1993). The influence of gender and age on Halstead-Reitan Neuropsychological Test performance. Journal of Gerontology: Psychological Sciences, 48, P278-P281.

Gur, R. C., Mozley, P. D., Resnick, S. M., Gottlieb, G. E., Kohn, M., Zimmerman, R., Herman, G., Atlas, S., Grossman, R., Berretta, D., ERwin, R., \& GuR, R. E. (1991). Gender differences in age effect on brain atrophy measured by magnetic resonance imaging. Proceedings of the National Academy of Sciences, 88, 2845-2849.

HALPERN, D. F. (1992). Sex differences in cognitive abilities. Hillsdale, NJ: Erlbaum

Hambrick, D. Z., Salthouse, T. A., \& Meinz, E. J. (1997). Predictors of crossword puzzle performance and moderators of age-cognition relations. Manuscript submitted for publication.

HEDGES, L. V., \& OLKIN, I. (1985). Statistical methods for meta-analysis. Orlando, FL: Academic Press.

Herlitz, A., Nilsson, L.-G., \& Bäckman, L. (1997). Gender differences in episodic memory. Memory \& Cognition, 25, 801-811.

HYDE, J. S. (1981). How large are cognitive gender differences? American Psychologist, 36, 892-901.

Hyde, J. S., Fennema, E., \& Lamon, S. J. (1990). Gender differences in mathematics performance: A meta-analysis. Psychological Bulletin, 107, 139-155.

HYDE, J. S., \& LINN, M. C. (1986). The psychology of gender: Advances through meta-analysis. Baltimore: Johns Hopkins University Press.

Kaye, J. A., DeCARLI, C., LuXenberg, J. S., \& RaPOPORT, S. I. (1992). The significance of age-related enlargement of the cerebral ventricles in healthy men and women measured by quantitative computed x-ray tomography. Joumal of the American Geriatrics Society, 40, 225-231.

LARRABEE, G. J., \& CROOK, T. H. (1993). Do men show more rapid ageassociated decline in simulated everyday verbal memory than do women? Psychology \& Aging, 8, 68-71.

Larrabee, G. J., Trahan, D. E., Curtiss, G., \& Levin, H. S. (1988). Normative data for the verbal selective reminding test. Neuropsychology, 2, 173-182.

Linn, M. C., \& Petersen, A. C. (1986). A meta-analysis of gender differences in spatial abilities: Implications for mathematics and science achievement. In J. S. Hyde \& M. C. Linn, (Eds.), The psychology of gender: Advances through meta-analysis (pp. 67-101). Baltimore: Johns Hopkins University Press.

MacCOBy, E. E., \& JACKLIN, C. N. (1974). The psychology of sex differences. Stanford, CA: Stanford University Press.

Meinz, E. J., \& Salthouse, T. A. (1998). The effects of age and experience on memory for visually presented music. Journal of Gerontology: Psychological Sciences, 53B, P60-P69.

Murphy, D. G. M., DeCarli, C., McIntosh, A. R., Daly, E., Mentis, M. J., Pietrini, P., Szczepanik, J., Schapiro, M. B., Grady, C. J., HoRwitz, B., \& RAPOPORT, S. I. (1996). Sex differences in human brain morphometry and metabolism: An in vivo quantitative magnetic resonance imaging and positron emission tomography study on the effect of aging. Archives of General Psychiarry, 53, 585-594.

Raz, N., Torres, I. J., \& ACKER, J. D. (1995). Age, gender, and hemispheric differences in human striatum: A quantitative review and new 
data from in vivo MRI morphometry. Neurobiology of Learning \& Memory, 63, 133-142.

Rosenthal, R. (1991). Meta-analytic procedures for social research. Beverly Hills, CA: Sage.

SALTHOUSE, T. A. (1991). Mediation of adult age differences in cognition by reductions in working memory and speed of processing. Psychological Science, 2, 179-183.

SALTHOUSE, T. A. (1992). Influence of processing speed on adult age differences in working memory. Acta Psychologica, 79, 155-170.

SAlthouse, T. A. (1993). Speed mediation of adult age differences in cognition. Developmental Psychology, 29, 722-738.

SAltHOUSE, T. A. (1994a). Aging associations: Influence of speed on adult age differences in associative learning. Journal of Experimental Psychology: Learning, Memory, \& Cognition, 20, 1486-1503.

SALThouse, T. A. (1994b). The nature of the influence of speed on adult age differences in cognition. Developmental Psychology, 30, 240-259.

SALTHOUSE, T. A. (1995a). Differential age-related influences on memory for verbal-symbolic information and visual-spatial information? Journal of Gerontology: Psychological Sciences, 50B, P193P201.

SAlthouse, T. A. (1995b). Influence of processing speed on adult age differences in learning. Swiss Journal of Psychology, 54, 102112 .

Salthouse, T. A. (1996). General and specific speed mediation of adult age differences in memory. Journal of Gerontology: Psychological Sciences, 51B, P30-P42.

Salthouse, T. A., \& Babcock, R. L. (1991). Decomposing adult age differences in cognition. Development Psychology, 27, 763-776.

Salthouse, T. A., Fristoe, N. M., Lineweaver, T. T., \& CoON, V. E. (1995). Aging of attention: Does the ability to divide decline? Memory \& Cognition, 23, 59-71.

Salthouse, T. A., Fristoe, N. M., \& Rhee, S. H. (1996). How localized are age-related effects on neuropsychological measures? Neuropsychology, 10, 272-285.

Salthouse, T. A., Hancock, H. E., Meinz, E. J., \& Hambrick, D. Z.
(1996). The influence of visual acuity on age-cognition relations. Journal of Gerontology: Psychological Science, 51B, P317-330.

Salthouse, T. A., Kausler, D. H., \& Saults, J. S. (1988). Investigation of student status, background variables, and the feasibility of standard tasks in cognitive aging research. Psychology \& Aging, 3, 29-37.

Salthouse, T. A., \& MeInZ, E. J. (1995). Aging, inhibition, working memory, and speed. Journal of Gerontology: Psychological Sciences, 50B, P297-P306.

Salthouse, T. A., \& Mitchell, D. R. D. (1990). Effects of age and naturally occurring experience on spatial visualization performance. Developmental Psychology, 26, 845-854.

SCHAIE, K. W. (1994). The course of adult intellectual development. American Psychologist, 49, 304-313.

SCHAIE, K. W. (1996). Intellectual development in adulthood: The Seattle longitudinal study. Cambridge: Cambridge University Press.

Verhaeghen, P., \& Salthouse, T. A. (1997). Meta-analyses of age-cognition relations in adulthood: Estimates of linear and nonlinear age effects and structural models. Psychological Bulletin, 122, 231-249.

WILLIS, S., \& SCHAIE, K. W. (1988). Gender differences in spatial abilities in old age: Longitudinal and intervention findings. Sex Roles, 18, 189-203.

Woodcocx, R. W., \& Johnson, M. B. (1989, 1990). Woodcock-Johnson Psycho-Educational Battery-Revised. Allen, TX: DLM.

\section{NOTES}

1. We would like to thank Richard W. Woodcock for generously sharing these data.

2. The $r_{\text {diff }}$ as used to express group differences could be converted to $t$ values by way of the formula $r^{2}=\sqrt{ } t^{2} /\left(t^{2}+d f\right)$.

3. Note that tests of the age $\times$ gender interaction are also possible by contrasting the $95 \%$ confidence intervals for the effect size estimates of the age relations for females and males. However, in order to express the age, gender, and age $\times$ gender effect sizes in a common metric, we focus on the analyses of interactions in terms of correlational units.

\section{APPENDIX A}

Task Descriptions

\begin{tabular}{|c|c|}
\hline Task & Description \\
\hline \multicolumn{2}{|l|}{ Speed } \\
\hline Letter comparison & $\begin{array}{l}\text { Write the letter } S \text { if pairs of letters are physically identical; otherwise, } \\
\text { write the letter } D \text {. }\end{array}$ \\
\hline Pattern comparison & $\begin{array}{l}\text { Write the letter } S \text { if pairs of line patterns are physically identical; } \\
\text { otherwise, write the letter D. }\end{array}$ \\
\hline Number comparison & $\begin{array}{l}\text { Indicate with a written response which pairs of numbers are physically } \\
\text { identical. }\end{array}$ \\
\hline Finding $A \mathrm{~s}$ & Mark with a written response the items that contain the letter $\mathrm{A}$. \\
\hline Digit symbol substitution & Write the symbol associated with a digit according to a code table. \\
\hline Number matching & $\begin{array}{l}\text { Mark with a written response which of several alternative sets of } \\
\text { numbers matches the target numbers. }\end{array}$ \\
\hline Pattern matching & $\begin{array}{l}\text { Mark with a written response which of several alternative sets } \\
\text { of patterns matches the target pattern. }\end{array}$ \\
\hline Letter completion & Write the letter that is missing from one of two pairs of letters. \\
\hline Number completion & Write the digit that is missing from one of two pairs of numbers. \\
\hline Number transformation & $\begin{array}{l}\text { Write the digit that would result by adding either } 1 \text { or } 2 \text { to the } \\
\text { displayed digit. }\end{array}$ \\
\hline Letter transformation & $\begin{array}{l}\text { Write the letter that would result by going one or two letters forward } \\
\text { in the alphabetic sequence. }\end{array}$ \\
\hline Digit copy & $\begin{array}{l}\text { Copy the displayed digit in the space immediately below } \\
\text { or adjacent to it. }\end{array}$ \\
\hline Number copy & $\begin{array}{l}\text { Copy the displayed number in the space immediately below } \\
\text { or adjacent to it. }\end{array}$ \\
\hline Letter copy & $\begin{array}{l}\text { Copy the displayed letter in the space immediately below } \\
\text { or adjacent to it. }\end{array}$ \\
\hline Symbol copy & $\begin{array}{l}\text { Copy the displayed symbol in the space immediately below } \\
\text { or adjacent to it. }\end{array}$ \\
\hline
\end{tabular}


APPENDIX A (Continued)

\begin{tabular}{ll}
\hline \multicolumn{1}{c}{ Task } & \multicolumn{1}{c}{ Description } \\
\hline Word copy & $\begin{array}{l}\text { Copy the displayed word in the space immediately below } \\
\text { or adjacent to it. } \\
\text { Draw a line to make a three-sided figure into a square or box. } \\
\text { Draw vertical lines through short horizontal lines, or draw horizontal } \\
\text { lines through short vertical lines. }\end{array}$ \\
Line marking & $\begin{array}{l}\text { Count backwards by a designated quantity (e.g., ones, threes, etc.). } \\
\text { Read visually presented words. }\end{array}$ \\
Naming time & Connect haphazardly positioned circles according to numerical or \\
Trail making & alternating numerical and alphabetical sequences. \\
Digit digit & $\begin{array}{l}\text { Press one key if two digits are identical; otherwise, press a different } \\
\text { key (speed). }\end{array}$ \\
Digit symbol & $\begin{array}{l}\text { Press one key if a digit and symbol match according to a code table; } \\
\text { otherwise, press a different key (speed). }\end{array}$ \\
Memory search & Classify a probe item with respect to whether it was (by pressing one \\
key) or was not (by pressing another key) in the previously presented \\
memory set (speed) (Sternberg memory search task). \\
Perform three simple arithmetic operations (psychophysically deter- \\
mined minimum time needed).
\end{tabular}

Spatial

Cube assembly

Paper folding

Spatial rotation

Block design

Object assembly

Surface development

Perceptual closure

Primary/Working Memory

Sentence span

Computation span

Word span

Digit span

Letter memory

Keeping track (numeric)

Keeping track (spatial)

Matrix memory (verbal)

Matrix memory (spatial)

Element memory (verbal)

Element memory (spatial)

$N$-back

Episodic Memory

Associative memory

Decide whether arrows on two of six connected boxes would point at one another if the boxes were assembled into a cube (speed and accuracy). Determine whether a particular pattern of holes would result if a piece of paper were folded in the designated fashion and a hole punched in the specified location (speed and accuracy).

Identify by a written response which of several alternative patterns is physically identical to the target pattern but merely rotated in the same plane (speed and accuracy).

Assemble a set of blocks to produce a pattern that matches the target pattern (speed).

Rearrange a set of puzzle pieces to form a complete object (speed). Determine the correspondence between designated positions across two- and three-dimensional drawings of the same object (speed and accuracy).

Identify objects from degraded pictures (speed and accuracy).

Remember the last word in each sentence while also answering questions about the sentences (accuracy).

Remember the last digit in each arithmetic problem while also solving the arithmetic problem (accuracy).

Remember as many words in sequence as possible (accuracy).

Remember as many digits in sequence as possible (accuracy).

Remember a sequence of three, five, or seven letters (accuracy).

Remember the latest value of a set of digits that are repeatedly updated by means of arithmetic operations (accuracy).

Remember the latest position of a set of asterisks that are repeatedly displaced by means of arrows of varying length and orientation (accuracy).

Remember the identities of 7 target letters from a set of 25 letters (accuracy).

Remember the positions of 7 target locations from a set of 25 positions (accuracy).

Decide whether a single letter was presented in an earlier memory set (accuracy).

Decide whether a single line segment was presented in an earlier line pattern (accuracy).

Report the digit $N$ items back in a sequence (where $N=0,1$, or 2 ) (accuracy).

Recognize whether elements of a particular pair (i.e., digits, letters, or symbols) were previously paired together when either member of the pair was last presented (accuracy). 
APPENDIX A (Continued)

\begin{tabular}{|c|c|}
\hline Task & Description \\
\hline Associative learning & $\begin{array}{l}\text { Select the second member of a pair of elements (i.e., digits, letters, or } \\
\text { symbols) when presented with the first member of the pair (accuracy). }\end{array}$ \\
\hline Name-number association & Remember the pairings between numbers and names (accuracy). \\
\hline Paired associate & $\begin{array}{l}\text { Recall the second member of a pair of words when presented with the } \\
\text { first member of the pair (accuracy). }\end{array}$ \\
\hline Free recall & $\begin{array}{l}\text { See or hear a list of } 12-20 \text { unrelated words and immediately attempt } \\
\text { to recall them in any order (accuracy). }\end{array}$ \\
\hline $\begin{array}{l}\text { RAVLT } \\
\text { (Rey auditory verbal learning test) }\end{array}$ & $\begin{array}{l}\text { Recall a set of } 15 \text { unrelated words with repeated study-recall } \\
\text { presentations (accuracy). }\end{array}$ \\
\hline Activity memory & $\begin{array}{l}\text { Recognize the order in which a set of activities was performed } \\
\text { in a session (accuracy). }\end{array}$ \\
\hline Frequency judgment & Decide the frequency with which words were presented (accuracy). \\
\hline Maze learning & $\begin{array}{l}\text { Make choice decisions across successive trials in a spatial maze } \\
\text { (accuracy). }\end{array}$ \\
\hline Temporal memory & $\begin{array}{l}\text { Reproduce the temporal order in which } 16 \text { words appeared } \\
\text { (accuracy). }\end{array}$ \\
\hline \multicolumn{2}{|r|}{ (t) } \\
\hline Raven's progressive matrices & $\begin{array}{l}\text { Select the best completion of the missing cell from a matrix } \\
\text { containing geometric patterns (accuracy). }\end{array}$ \\
\hline Number series completion & Identify the best continuation of a series of numbers (accuracy). \\
\hline Integrative reasoning & $\begin{array}{l}\text { Decide the truth of a statement pertaining to two elements given a set } \\
\text { of premises describing relations among premises (accuracy). }\end{array}$ \\
\hline Geometric analogies & $\begin{array}{l}\text { Decide which of several alternatives represents the best } D \text { term for } \\
\text { A:B is to C:D1,D2,D3, with stimuli consisting of geometric patterns } \\
\text { (accuracy). }\end{array}$ \\
\hline PMA reasoning & Complete a series of numerical items (accuracy). \\
\hline Shipley abstraction & Complete a series of numerical and verbal items (accuracy). \\
\hline Cattell's matrices & $\begin{array}{l}\text { Select the best item for completion of the missing cell from a matrix } \\
\text { containing geometric patterns (accuracy). }\end{array}$ \\
\hline Letter sets & Decide which set of letters does not fit with the others (accuracy). \\
\hline \multicolumn{2}{|r|}{ 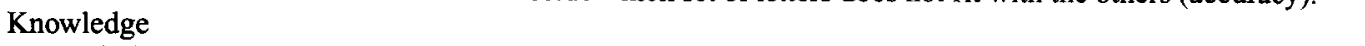 } \\
\hline Vocabulary & $\begin{array}{l}\text { Select which alternative is the best synonym or antonym of the target } \\
\text { word (accuracy). }\end{array}$ \\
\hline Shipley vocabulary & $\begin{array}{l}\text { Select which alternative is the best synonym or antonym of the target } \\
\text { word (accuracy). }\end{array}$ \\
\hline General information & $\begin{array}{l}\text { Select which alternative is the best answer to questions on a variety of } \\
\text { topics ranging from American History, to Geography, Mythology, } \\
\text { Music, and World Literature (accuracy). }\end{array}$ \\
\hline \multicolumn{2}{|l|}{ Verbal Fluency } \\
\hline Letter fluency & $\begin{array}{l}\text { Generate words that begin with a specified letter (number generated } \\
\text { within a specifed amount of time). }\end{array}$ \\
\hline Sequential associates & $\begin{array}{l}\text { Generate words that are associates of the preceding item (number } \\
\text { generated within a specified amount of time). }\end{array}$ \\
\hline Make words & $\begin{array}{l}\text { Create as many words as possible from a set of letters (number } \\
\text { created within a specified amount of time). }\end{array}$ \\
\hline \multicolumn{2}{|l|}{ Miscellaneous } \\
\hline Arithmetic computation & Carry out elementary arithmetic operations (speed and accuracy). \\
\hline Sentence comprehension & $\begin{array}{l}\text { Answer simple verbal comprehension questions (speed and } \\
\text { accuracy). }\end{array}$ \\
\hline Stroop interference (color) & $\begin{array}{l}\text { Name ink colors when the targets are words of different colors } \\
\text { (speed). }\end{array}$ \\
\hline Stroop interference (position) & $\begin{array}{l}\text { Name target positions when the targets are words indicating different } \\
\text { positions (speed). }\end{array}$ \\
\hline Stroop interference (number) & $\begin{array}{l}\text { Name the number of elements when the elements are digits } \\
\text { representing different numbers (speed). }\end{array}$ \\
\hline Anagram & Rearrange a set of letters to make a word (number completed). \\
\hline
\end{tabular}


APPENDIX B

Age and Gender Relations from Individual

Studies in the Primary Analysis

\begin{tabular}{|c|c|c|c|c|c|c|}
\hline \multirow[b]{2}{*}{ Study } & \multirow[b]{2}{*}{$j$} & \multirow[b]{2}{*}{ Gender $r$} & \multirow[b]{2}{*}{ Age $r$} & \multicolumn{2}{|c|}{ Age Correlation $(r)$} & \multirow{2}{*}{$\begin{array}{c}\text { Gender Difference } \\
\text { in Age } r\end{array}$} \\
\hline & & & & Male & Female & \\
\hline \multicolumn{7}{|c|}{ Speed Tasks } \\
\hline 1 & 3 & -.10 & -.48 & -.48 & -.47 & -.01 \\
\hline 2 & 2 & .07 & -.51 & -.52 & -.50 & .00 \\
\hline 3 & 2 & .05 & -.62 & -.73 & -.56 & -.17 \\
\hline 4 & 4 & .05 & -.47 & -.46 & -.48 & .02 \\
\hline 5 & 3 & .06 & -.56 & -.54 & -.58 & .05 \\
\hline 6 & 3 & .09 & -.64 & -.59 & -.72 & .23 \\
\hline 7 & 3 & .05 & -.55 & -.56 & -.55 & -.01 \\
\hline 8 & 3 & .03 & -.60 & -.54 & -.61 & .10 \\
\hline 9 & 10 & .00 & -.45 & -.35 & -.54 & .23 \\
\hline 10 & 6 & -.01 & -.52 & -.56 & -.49 & -.09 \\
\hline 11 & 7 & .15 & -.39 & -.41 & -.38 & -.05 \\
\hline 12 & 6 & .03 & -.49 & -.50 & -.49 & -.01 \\
\hline 13 & 8 & -.05 & -.35 & -.27 & -.40 & .14 \\
\hline 14 & 7 & .00 & -.50 & -.53 & -.48 & -.06 \\
\hline 15 & 7 & .12 & -.52 & -.50 & -.55 & .07 \\
\hline 16 & 10 & .03 & -.58 & -.58 & -.58 & .00 \\
\hline 18 & 3 & .17 & -.60 & -.54 & -.64 & .16 \\
\hline 19 & 6 & .01 & -.59 & -.56 & -.68 & .20 \\
\hline 20 & 7 & -.01 & -.56 & -.52 & -.58 & .09 \\
\hline 21 & 4 & .11 & -.46 & -.40 & -.50 & .13 \\
\hline 22 & 2 & .18 & -.52 & -.60 & -.46 & -.19 \\
\hline 23 & 2 & .10 & -.53 & -.60 & -.48 & -.17 \\
\hline 24 & 8 & -.11 & -.54 & -.50 & -.49 & -.01 \\
\hline 25 & 2 & .15 & -.24 & -.18 & -.34 & .17 \\
\hline \multicolumn{7}{|c|}{ Spatial Tasks } \\
\hline 3 & 1 & -.20 & -.38 & -.35 & -.43 & .09 \\
\hline 6 & 2 & -.14 & -.17 & -.18 & -.13 & -.05 \\
\hline 7 & 2 & -.08 & -.34 & -.41 & -.26 & -.17 \\
\hline 9 & 1 & -.22 & -.39 & -.32 & -.43 & .13 \\
\hline 12 & 2 & -.24 & -.38 & -.35 & -.39 & .04 \\
\hline 13 & 1 & -.13 & -.28 & -.19 & -.33 & .15 \\
\hline 15 & 1 & -.18 & -.43 & -.53 & -.41 & -.15 \\
\hline 20 & 3 & -.14 & -.46 & -.47 & -.46 & -.01 \\
\hline 22 & 2 & -.10 & -.24 & -.25 & -.23 & -.02 \\
\hline 24 & 1 & -.32 & -.48 & -.59 & -.39 & -.26 \\
\hline 25 & 2 & -.18 & -.34 & -.25 & -.41 & .17 \\
\hline \multicolumn{7}{|c|}{ Primary/Working Memory } \\
\hline 5 & 2 & -.09 & -.48 & -.53 & -.45 & -.09 \\
\hline 6 & 2 & -.01 & -.46 & -.48 & -.44 & -.05 \\
\hline 7 & 2 & -.07 & -.42 & -.41 & -.42 & .01 \\
\hline 8 & 2 & .04 & -.34 & -.35 & -.34 & -.01 \\
\hline 14 & 6 & -.06 & -.43 & -.39 & -.47 & .09 \\
\hline 15 & 2 & -.09 & -.32 & -.43 & -.25 & -.21 \\
\hline 16 & 1 & -.07 & -.54 & -.47 & -.62 & .21 \\
\hline 17 & 4 & -.11 & -.44 & -.51 & -.39 & -.16 \\
\hline 18 & 4 & -.01 & -.33 & -.23 & -.41 & .20 \\
\hline 19 & 1 & -.05 & -.36 & -.28 & -.48 & .23 \\
\hline 21 & 3 & -.06 & -.26 & -.28 & -.25 & -.05 \\
\hline 22 & 2 & -.08 & -.42 & -.43 & -.41 & -.02 \\
\hline 23 & 2 & -.12 & -.41 & -.44 & -.38 & -.07 \\
\hline 24 & 2 & -.11 & -.16 & -.17 & -.15 & -.01 \\
\hline
\end{tabular}


APPENDIX B (Continued)

\begin{tabular}{|c|c|c|c|c|c|c|}
\hline \multirow[b]{2}{*}{ Study } & \multirow[b]{2}{*}{$j$} & \multirow[b]{2}{*}{ Gender $r$} & \multirow[b]{2}{*}{ Age $r$} & \multicolumn{2}{|c|}{ Age Correlation $(r)$} & \multirow{2}{*}{$\begin{array}{c}\text { Gender Difference } \\
\text { in Age } r\end{array}$} \\
\hline & & & & Male & Female & \\
\hline \multicolumn{7}{|c|}{ Episodic Memory } \\
\hline 9 & 2 & .08 & -.40 & -.38 & -.43 & .06 \\
\hline 10 & 2 & -.01 & -.35 & -.39 & -.32 & -.09 \\
\hline 11 & 2 & .11 & -.25 & -.15 & -.35 & .21 \\
\hline 12 & 2 & .08 & -.27 & -.24 & -.31 & .07 \\
\hline 13 & 1 & .04 & -.27 & -.22 & -.31 & .10 \\
\hline 14 & 1 & -.09 & -.41 & -.31 & -.49 & .21 \\
\hline 15 & 2 & -.04 & -.33 & -.40 & -.30 & -.11 \\
\hline 16 & 2 & .17 & -.52 & -.50 & -.57 & .09 \\
\hline 20 & 2 & .12 & -.50 & -.55 & -.48 & -.10 \\
\hline 21 & 1 & -.19 & -.33 & -.38 & -.35 & -.03 \\
\hline 22 & 3 & .04 & -.23 & -.28 & -.19 & -.09 \\
\hline 23 & 3 & .05 & -.29 & -.32 & -.27 & -.05 \\
\hline
\end{tabular}

Reasoning

$\begin{array}{rrrrrrr}1 & 2 & -.16 & -.42 & -.33 & -.44 & .13 \\ 2 & 2 & .04 & -.50 & -.58 & -.44 & -.19 \\ 3 & 1 & .00 & -.67 & -.65 & -.68 & .05 \\ 5 & 2 & -.11 & -.35 & -.35 & -.35 & .00 \\ 6 & 2 & -.03 & -.42 & -.38 & -.47 & .11 \\ 7 & 2 & -.13 & -.46 & -.49 & -.41 & -.10 \\ 9 & 3 & -.02 & -.35 & -.22 & -.44 & .25 \\ 12 & 2 & -.16 & -.37 & -.40 & -.31 & -.10 \\ 13 & 1 & -.05 & -.09 & .14 & -.25 & .38 \\ 20 & 1 & .00 & -.45 & -.46 & -.44 & -.03 \\ 23 & 2 & -.33 & -.36 & -.37 & -.36 & -.01 \\ 25 & 2 & -.03 & -.26 & -.18 & -.33 & .16\end{array}$

Knowledge

$\begin{array}{rrrrrrr}1 & 2 & -.04 & .27 & .31 & .27 & .04 \\ 2 & 2 & -.08 & .12 & .05 & .16 & -.12 \\ 3 & 2 & -.07 & .13 & .13 & .12 & .01 \\ 16 & 1 & -.03 & .17 & .25 & .13 & .12 \\ 19 & 1 & .02 & .52 & .59 & .39 & .26 \\ 20 & 1 & .01 & .25 & .19 & .28 & -.10 \\ 21 & 1 & -.06 & .23 & .19 & .26 & -.07\end{array}$

Verbal Fluency

$\begin{array}{rrrrrrr}1 & 2 & -.01 & -.11 & -.06 & -.13 & .08 \\ 2 & 2 & -.02 & -.18 & -.33 & -.10 & -.24 \\ 16 & 1 & .17 & .24 & .34 & .19 & .16\end{array}$

\begin{tabular}{rrrrrrr}
1 & 1 & .01 & .04 & .10 & .00 & .10 \\
16 & 1 & .03 & -.60 & -.63 & -.58 & -.08 \\
17 & 2 & .05 & -.55 & -.58 & -.51 & -.09 \\
18 & 2 & .10 & -.46 & -.38 & -.51 & .16 \\
24 & 3 & .16 & -.31 & -.30 & -.32 & .03 \\
\hline
\end{tabular}

Note-For study numbers, see Table $1 ; j$, number of variables contributing to effect size; gender $r$, point-biserial correlation with gender $($ male $=0$, female $=1)$; age $r$, correlation with chronological age; age $r$ for males/females, see Table 1 for number of male and female participants; gender difference in age $r$, age $\times$ gender interaction term expressed as $r_{\text {age }}($ male $)-r_{\text {age }}($ female $)$. 
APPENDIX C

Standard Deviations for Age and

Task Classification According to Gender

\begin{tabular}{|c|c|c|c|c|c|c|c|}
\hline \multirow[b]{3}{*}{ Study } & \multirow[b]{3}{*}{$d f$} & \multicolumn{3}{|c|}{ Age } & \multicolumn{3}{|c|}{ Dependent Variable } \\
\hline & & \multicolumn{2}{|c|}{$S D$} & \multirow[b]{2}{*}{$F$} & \multicolumn{2}{|c|}{$S D$} & \multirow[b]{2}{*}{$F$} \\
\hline & & $\overline{\text { Male }}$ & Female & & Male & Female & \\
\hline \multicolumn{8}{|c|}{ Speed } \\
\hline 1 & $(58,142)$ & 19.90 & 17.31 & 1.32 & 0.76 & 0.87 & 1.33 \\
\hline 2 & $(90,126)$ & 13.30 & 14.17 & 1.14 & 0.85 & 0.94 & 1.22 \\
\hline 3 & $(85,108)$ & 15.33 & 16.12 & 1.11 & 0.91 & 0.90 & 1.02 \\
\hline 4 & $(42,84)$ & 17.42 & 14.65 & 1.41 & 0.82 & 0.73 & 1.26 \\
\hline 5 & $(85,134)$ & 18.72 & 16.57 & 1.28 & 0.89 & 0.91 & 1.03 \\
\hline 6 & $(124,102)$ & 18.06 & 17.21 & 1.10 & 0.89 & 0.93 & 1.09 \\
\hline 7 & $(109,112)$ & 18.11 & 17.14 & 1.12 & 0.89 & 0.90 & 1.03 \\
\hline 8 & $(52,46)$ & 18.44 & 16.41 & 1.26 & 0.78 & 0.98 & 1.57 \\
\hline 9 & $(123,180)$ & 17.09 & 16.33 & 1.09 & 0.59 & 0.63 & 1.16 \\
\hline 10 & $(85,153)$ & 16.14 & 15.89 & 1.03 & 0.84 & 0.75 & 1.28 \\
\hline 11 & $(59,64)$ & 17.20 & 15.82 & 1.18 & 0.54 & 0.55 & 1.03 \\
\hline 12 & $(94,150)$ & 17.63 & 16.49 & 1.14 & 0.81 & 0.80 & 1.02 \\
\hline 13 & $(101,155)$ & 17.64 & 16.48 & 1.14 & 0.66 & 0.71 & 1.17 \\
\hline 14 & $(79,92)$ & 20.40 & 18.99 & 1.15 & 0.95 & 0.85 & 1.27 \\
\hline 15 & $(59,56)$ & 15.62 & 16.79 & 1.16 & 0.80 & 0.74 & 1.18 \\
\hline 16 & $(60,116)$ & 20.60 & 19.89 & 1.07 & 0.60 & 0.55 & 1.17 \\
\hline 18 & $(93,138)$ & 17.69 & 16.22 & 1.07 & 0.84 & 0.94 & 1.25 \\
\hline 19 & $(79,50)$ & 20.47 & 19.46 & 1.11 & 0.77 & 0.82 & 1.14 \\
\hline 20 & $(163,94)$ & 17.67 & 18.89 & 1.14 & 0.66 & 0.75 & 1.32 \\
\hline 21 & $(82,113)$ & 18.67 & 16.17 & 1.33 & 0.81 & 0.82 & 1.02 \\
\hline 22 & $(57,70)$ & 16.85 & 16.07 & 1.10 & 1.08 & 0.68 & $2.52^{*}$ \\
\hline 23 & $(107,124)$ & 17.41 & 17.21 & 1.02 & 0.80 & 0.99 & 1.55 \\
\hline 24 & $(101,109)$ & 18.89 & 16.39 & 1.33 & 0.73 & 0.74 & 1.02 \\
\hline 25 & $(185,196)$ & 16.93 & 16.44 & 1.06 & 0.85 & 0.83 & 1.05 \\
\hline \multicolumn{8}{|c|}{ Spatial } \\
\hline 3 & $(85,108)$ & 15.33 & 16.12 & 1.11 & 1.00 & 0.95 & 1.11 \\
\hline 6 & $(124,102)$ & 18.06 & 17.21 & 1.10 & 0.81 & 0.74 & 1.19 \\
\hline 7 & $(109,112)$ & 18.11 & 17.14 & 1.12 & 0.74 & 0.65 & 1.27 \\
\hline 9 & $(123,180)$ & 17.09 & 16.33 & 1.09 & 1.00 & 1.04 & 1.08 \\
\hline 12 & $(94,150)$ & 17.63 & 16.49 & 1.14 & 0.90 & 0.73 & 1.50 \\
\hline 13 & $(101,155)$ & 17.64 & 16.48 & 1.14 & 1.00 & 1.04 & 1.08 \\
\hline 15 & $(59,56)$ & 15.62 & 16.79 & 1.16 & 1.00 & 0.98 & 1.04 \\
\hline 20 & $(163,94)$ & 17.67 & 18.89 & 1.14 & 0.83 & 0.87 & 1.10 \\
\hline 22 & $(57,70)$ & 16.85 & 16.07 & 1.10 & 0.78 & 0.76 & 1.07 \\
\hline 24 & $(101,109)$ & 18.89 & 16.39 & 1.33 & 1.05 & 0.88 & 1.41 \\
\hline 25 & $(185,196)$ & 16.93 & 16.44 & 1.06 & 0.95 & 0.85 & 1.24 \\
\hline \multicolumn{8}{|c|}{ Primary/Working Memory } \\
\hline 5 & $(85,134)$ & 18.72 & 16.57 & 1.28 & 0.94 & 0.83 & 1.28 \\
\hline 6 & $(124,102)$ & 18.06 & 17.21 & 1.10 & 0.91 & 0.90 & 1.01 \\
\hline 7 & $(109,112)$ & 18.11 & 17.14 & 1.12 & 0.94 & 0.86 & 1.19 \\
\hline 8 & $(52,46)$ & 18.44 & 16.41 & 1.26 & 0.92 & 0.87 & 1.12 \\
\hline 14 & $(79,92)$ & 20.40 & 18.99 & 1.15 & 0.39 & 0.35 & 1.22 \\
\hline 15 & $(59,56)$ & 15.62 & 16.79 & 1.16 & 0.89 & 0.78 & 1.28 \\
\hline 16 & $(60,116)$ & 20.60 & 19.89 & 1.07 & 1.16 & 0.91 & 1.63 \\
\hline 17 & $(110,115)$ & 18.47 & 15.12 & 1.49 & 0.92 & 0.73 & 1.59 \\
\hline 18 & $(93,138)$ & 16.79 & 16.22 & 1.07 & 0.77 & 0.81 & 1.10 \\
\hline 19 & $(79,50)$ & 20.47 & 19.46 & 1.11 & 0.97 & 1.04 & 1.14 \\
\hline 21 & $(82,113)$ & 18.67 & 16.17 & 1.33 & 0.78 & 0.79 & 1.02 \\
\hline 22 & $(57,70)$ & 16.85 & 16.07 & 1.10 & 0.81 & 0.82 & 1.02 \\
\hline 23 & $(107,124)$ & 17.41 & 17.21 & 1.02 & 0.82 & 0.82 & 1.02 \\
\hline 24 & $(101,109)$ & 18.89 & 16.39 & 1.33 & 0.92 & 0.85 & 1.17 \\
\hline
\end{tabular}


APPENDIX C (Continued)

\begin{tabular}{|c|c|c|c|c|c|c|c|}
\hline \multirow[b]{3}{*}{ Study } & \multirow[b]{3}{*}{$d f$} & \multicolumn{3}{|c|}{ Age } & \multicolumn{3}{|c|}{ Dependent Variable } \\
\hline & & \multicolumn{2}{|c|}{$S D$} & \multirow[b]{2}{*}{$F$} & \multicolumn{2}{|c|}{$S D$} & \multirow[b]{2}{*}{$F$} \\
\hline & & Male & Female & & Male & Female & \\
\hline \multicolumn{8}{|c|}{ Episodic Memory } \\
\hline 9 & $(123,180)$ & 17.09 & 16.33 & 1.09 & 0.89 & 0.95 & 1.14 \\
\hline 10 & $(85,153)$ & 16.14 & 15.89 & 1.03 & 0.83 & 0.83 & 1.01 \\
\hline 11 & $(59,64)$ & 17.20 & 15.82 & 1.18 & 0.86 & 0.89 & 1.07 \\
\hline 12 & $(94,150)$ & 17.63 & 16.49 & 1.14 & 0.75 & 0.75 & 1.02 \\
\hline 13 & $(101,155)$ & 17.64 & 16.48 & 1.14 & 1.03 & 0.98 & 1.12 \\
\hline 14 & $(79,92)$ & 20.40 & 18.99 & 1.15 & 0.94 & 1.08 & 1.32 \\
\hline 15 & $(59,56)$ & 15.62 & 16.79 & 1.16 & 0.93 & 0.83 & 1.26 \\
\hline 16 & $(60,116)$ & 20.60 & 19.89 & 1.07 & 0.87 & 0.88 & 1.04 \\
\hline 20 & $(163,94)$ & 17.67 & 18.89 & 1.14 & 0.88 & 0.89 & 1.02 \\
\hline 21 & $(82,113)$ & 18.67 & 16.17 & 1.33 & 1.14 & 0.82 & $1.95^{*}$ \\
\hline 22 & $(57,70)$ & 16.85 & 16.07 & 1.10 & 0.69 & 0.70 & 1.02 \\
\hline 23 & $(107,124)$ & 17.41 & 17.21 & 1.02 & 0.68 & 0.68 & 1.00 \\
\hline \multicolumn{8}{|c|}{ Reasoning } \\
\hline 1 & $(58,142)$ & 19.90 & 17.31 & 1.32 & 0.90 & 0.92 & 1.05 \\
\hline 2 & $(90,126)$ & 13.30 & 14.17 & 1.14 & 0.95 & 0.80 & 1.42 \\
\hline 3 & $(85,108)$ & 15.33 & 16.12 & 1.11 & 1.00 & 0.99 & 1.01 \\
\hline 5 & $(85,134)$ & 18.73 & 16.57 & 1.28 & 0.84 & 0.91 & 1.18 \\
\hline 6 & $(124,102)$ & 18.06 & 17.21 & 1.10 & 0.81 & 0.77 & 1.11 \\
\hline 7 & $(109,112)$ & 18.11 & 17.14 & 1.12 & 0.74 & 0.66 & 1.27 \\
\hline 9 & $(123,180)$ & 17.09 & 16.33 & 1.09 & 1.07 & 1.12 & 1.08 \\
\hline 12 & $(94,150)$ & 17.63 & 16.49 & 1.14 & 0.95 & 0.78 & 1.48 \\
\hline 13 & $(101,155)$ & 17.64 & 16.48 & 1.14 & 1.01 & 1.00 & 1.02 \\
\hline 20 & $(163,94)$ & 17.67 & 18.89 & 1.14 & 0.98 & 1.02 & 1.09 \\
\hline 23 & $(107,124)$ & 17.41 & 17.21 & 1.02 & 0.90 & 0.84 & 1.13 \\
\hline 25 & $(185,196)$ & 16.93 & 16.44 & 1.06 & 0.91 & 0.92 & 1.01 \\
\hline \multicolumn{8}{|c|}{ Knowledge } \\
\hline 1 & $(58,142)$ & 19.90 & 17.31 & 1.32 & 0.94 & 0.96 & 1.04 \\
\hline 2 & $(90,126)$ & 13.30 & 14.17 & 1.14 & 0.82 & 0.96 & 1.35 \\
\hline 3 & $(85,108)$ & 15.33 & 16.12 & 1.11 & 0.83 & 0.93 & 1.26 \\
\hline 16 & $(60,116)$ & 20.60 & 19.89 & 1.07 & 0.98 & 1.01 & 1.07 \\
\hline 19 & $(79,50)$ & 20.47 & 19.46 & 1.11 & 1.03 & 0.98 & 1.10 \\
\hline 20 & $(163,94)$ & 17.67 & 18.89 & 1.14 & 0.99 & 1.01 & 1.05 \\
\hline 21 & $(82,113)$ & 18.67 & 16.17 & 1.33 & 0.99 & 0.99 & 1.02 \\
\hline \multicolumn{8}{|c|}{ Verbal Fluency } \\
\hline 1 & $(58,142)$ & 19.90 & 17.31 & 1.32 & 1.02 & 0.87 & 1.35 \\
\hline 2 & $(90,126)$ & 13.30 & 14.17 & 1.14 & 0.82 & 0.94 & 1.32 \\
\hline 16 & $(60,116)$ & 20.60 & 19.89 & 1.07 & 0.80 & 1.08 & 1.82 \\
\hline \multicolumn{8}{|c|}{ Miscellaneous } \\
\hline 1 & $(58,142)$ & 19.90 & 17.31 & 1.32 & 1.04 & 0.99 & 1.12 \\
\hline 2 & $(90,126)$ & 13.30 & 14.17 & 1.14 & 0.91 & 1.05 & 1.33 \\
\hline 16 & $(60,116)$ & 20.60 & 19.89 & 1.07 & 1.14 & 0.94 & 1.46 \\
\hline 17 & $(110,115)$ & 18.47 & 15.12 & 1.49 & 0.95 & 0.88 & 1.16 \\
\hline 18 & $(93,138)$ & 16.79 & 16.22 & 1.07 & 0.85 & 0.95 & 1.26 \\
\hline 24 & $(101,109)$ & 18.89 & 16.39 & 1.33 & 0.61 & 0.84 & $1.91^{*}$ \\
\hline
\end{tabular}

Note-The $F$ tests were computed by dividing the larger variance value (females or males) by the smaller variance value. $d f=$ (number of males -1 , number of females -1$) . \quad{ }^{*} p<.05$.

(Manuscript received January 31, 1997;

revision accepted for publication September 9,1997.) 